\title{
Prevalence and awareness of chronic kidney disease among adult diabetic outpatients in Northeast Ethiopia
}

\author{
Temesgen Fiseha ${ }^{1}$ and Zemenu Tamir ${ }^{2 *}$
}

\begin{abstract}
Background: Chronic kidney disease (CKD) is a serious complication of diabetes associated with adverse outcomes of renal failure, cardiovascular disease and mortality. Despite this, data regarding the burden and awareness of CKD among adults with diabetes in Sub-Saharan Africa countries are lacking. The aim of this study was, therefore to determine the prevalence and awareness of CKD among diabetic outpatients attending a hospital in Northeast Ethiopia.

Methods: We conducted a cross-sectional study on 323 diabetic adults at the diabetes clinic of a hospital in Northeast Ethiopia, from February 1 to July 30, 2016. Each patient provided a blood sample for serum creatinine and urine for albuminuria. Glomerular filtration rate (eGFR) was estimated using the Modification of Diet in Renal Disease (MDRD) equation. CKD was defined as eGFR $<60 \mathrm{ml} / \mathrm{min} / 1.73 \mathrm{~m}^{2}$ and/or albuminuria. Awareness was defined as a positive response to "Has a doctor or other health care professional ever told you that you had kidney disease?"
\end{abstract}

Results: Of the 323 patients, 85 (26.3\%) had Stage 1-5 CKD, 42 (13.0\%) had eGFR $<60 \mathrm{ml} / \mathrm{min} / 1.73 \mathrm{~m}^{2}$ and 58 (18.0\%) had albuminuria. In patients with eGFR $<60 \mathrm{ml} / \mathrm{min} / 1.73 \mathrm{~m}^{2}$ (stage $3-5 \mathrm{CKD}$ ), serum creatinine was abnormal (> $1.5 \mathrm{mg} / \mathrm{dl}$ ) in $23.5 \%$ and albuminuria was absent in $31.8 \%$. Of the patients with CKD, only $10.6 \%$ of them were aware of their CKD. The proportion of patients who were aware of their disease increased with worsening of CKD stages, from $3.4 \%$ of with stage 1 to $75.0 \%$ with stage 4 . Awareness for all individuals with advanced stages of CKD was only $11.9 \%$. Having albuminuria, high serum creatinine, a family history of kidney disease and being obese were significantly associated with CKD awareness.

Conclusion: A high prevalence but low awareness of CKD was found in diabetic outpatients attending our clinic in Northeast Ethiopia. Our results highlight the need for more diagnostic strategies for CKD screening among diabetic adults and primary care education on the impact of detecting CKD in the early stage to prevent adverse outcomes and improve diabetes care.

Keywords: Chronic kidney disease, CKD awareness, Estimated glomerular filtration rate, Diabetes

\footnotetext{
* Correspondence: zemenut266@gmail.com

${ }^{2}$ Department of Medical Laboratory Sciences, College of Health Sciences,

Addis Ababa University, Addis Ababa, Ethiopia

Full list of author information is available at the end of the article
}

(c) The Author(s). 2020 Open Access This article is licensed under a Creative Commons Attribution 4.0 International License, which permits use, sharing, adaptation, distribution and reproduction in any medium or format, as long as you give appropriate credit to the original author(s) and the source, provide a link to the Creative Commons licence, and indicate if changes were made. The images or other third party material in this article are included in the article's Creative Commons licence, unless indicated otherwise in a credit line to the material. If material is not included in the article's Creative Commons licence and your intended use is not permitted by statutory regulation or exceeds the permitted use, you will need to obtain permission directly from the copyright holder. To view a copy of this licence, visit http://creativecommons.org/licenses/by/4.0/ The Creative Commons Public Domain Dedication waiver (http://creativecommons.org/publicdomain/zero/1.0/) applies to the data made available in this article, unless otherwise stated in a credit line to the data. 


\section{Background}

Chronic Kidney Disease (CKD) is a global public health problem associated with an increased risk of end stage renal disease (ESRD), cardiovascular disease (CVD) and premature mortality [1]. It is estimated to affect 8 to $16 \%$ of the adult populations of the world, and most of the global burden is occurring in low- and middleincome countries, leading to significant morbidity and mortality due to undertreated CVD and kidney failure $[2,3]$.

CKD is a well recognised and serious complication of diabetes and diabetes is one of the most common causes of CKD, with up to $44 \%$ of patients with CKD affected by diabetes [4]. The presence of CKD in diabetes is associated with an increased risk of CVD, all cause and cardiovascular mortality, and kidney failure; requiring costly renal replacement therapy $[5,6]$. It is also associated with significantly higher total all-cause health care costs and costs directly related to treatment of CKD in diabetes $[7,8]$. Moreover, due to the rapidly rising incidence of diabetes, the prevalence of CKD as well as the already high medical costs of renal therapy in patients with diabetes are expected to rise further, adding to the global burden of disease and health-care expenditure [9, 10].

Although CKD is common in diabetes and caries a high risk of adverse outcomes, it is often unrecognized; up to $77 \%$ of patients receiving diabetes management may have undiagnosed CKD [11, 12]. In addition, because CKD is usually silent until advanced stages, many people with CKD are unaware of its presence and it is identified in its later stages, when opportunities to prevent adverse outcomes are limited [13, 14]. Detection of CKD during its early stages provides opportunity for therapeutic interventions to prevent or delay the onset of complications and improve outcomes [15]. And since lifestyle factors influence the risk of CKD; disease awareness and education on risk are essential for optimal management to prevent or reduce the progression of early CKD, cardiovascular events and mortality [16-18].

Despite existing evidence suggesting that CKD is a substantial health burden among diabetic patients on the African continent [19], data regarding the burden and awareness of CKD among adults with diabetes in SubSaharan Africa are lacking. Therefore, in this study we aimed to determine the prevalence and awareness of CKD among diabetic adult outpatients attending a hospital in Northeast Ethiopia.

\section{Methods}

\section{Study setting and population}

This cross-sectional study was conducted from February 1 to July 30, 2016 at the outpatient diabetes clinic of Dessie Referral Hospital (DRH), Northeast Ethiopia. The
Hospital is found in Dessie town of Amhara regional state and serves as a referral center for South Wollo and surrounding zones. It delivers diagnostic, therapeutic and monitoring services to all diabetic patients and also tertiary diabetes patient care. Adult patients (aged $\geq 18$ years) already diagnosed with diabetes mellitus attending the follow-up diabetes clinic of the hospital during the study period were included in the study. Diabetic patients who were hospitalized, pregnant (woman), with acute illness (fever), underwent treatment with dialysis and not fasting were excluded from the study. The study protocol was approved by the Institutional Review Board and Research Ethics Committee of Wollo University, College of Medicine and Health Sciences. An informed written consent was obtained from all the participants enrolled.

\section{Sample size}

The sample size calculation was based on an estimated prevalence of CKD of $50 \%$ in that population, with a confidence level of 95 and 5\% precision. A sample size of at least 317 individuals was needed to be representative of the 1800 individuals on diabetic follow-up in our site to obtain $80 \%$ power. Considering a 5\% nonresponse rate, the sample size was increased to 333 patients. Estimates of CKD prevalence were obtained on the 323 participants. Systematic random sampling was used to select study participants.

\section{Data collection and laboratory measurements}

Data on socio-demographic, medical and family history were collected by using a pre-tested structured interviewer administered questionnaire (see supplementary file 1). Participants who completed the interview process had their anthropometric data such as weight (kilograms), height (meters), and blood pressure (mm $\mathrm{Hg}$ ) collected. Body mass index (BMI) was calculated as the ratio of the weight $(\mathrm{kg})$ to the square of the height (meters) and classified as: normal/underweight (BMI < 25 $\mathrm{kg} / \mathrm{m}^{2}$ ), overweight (BMI $25-29.9 \mathrm{~kg} / \mathrm{m}^{2}$ ) and obese (BMI $\geq 30 \mathrm{~kg} / \mathrm{m}^{2}$ ). Blood pressure (BP) was measured using a manual mercury sphygmomanometer, with the patient remaining in a sitting position for at least $15 \mathrm{~min}$ before the first measurement. Each participant's blood pressure was measured three times at an interval of at least $5 \mathrm{~min}$, and then averaged to be recorded. Hypertension was defined as systolic BP $\geq 140 \mathrm{mmHg}$ and/or diastolic BP $\geq 90 \mathrm{mmHg}$ or current use of antihypertensive medication. Awareness of kidney disease was ascertained by asking the question "Have you ever been told that you had a kidney disease by a doctor or other health care professional?" Do not include kidney stones or bladder infection. 
Blood samples were drawn early in the morning after an overnight fasting and biochemical analyses were performed on Dirui CS-T240 clinical chemistry analyzer (Dirui Industrial Company, China) using kits supplied by the manufacturer. Blood glucose was measured by enzymatic GOD-PAP method. Serum creatinine was measured using a Jaffe kinetic method, with calibration traceable to IDMS reference material. Fresh urine sample was collected from each participant to detect albuminuria using dipsticks (COMBINA 11S, Human). Presence of albuminuria ( +1 or more) in urine was defined as albuminuria.

The four-variable Modification of Diet in Renal Disease (MDRD) study equation was used to estimate glomerular filtration rate (eGFR) [20]. CKD was defined as eGFR $<60 \mathrm{ml} / \mathrm{min} / 1.73 \mathrm{~m}^{2}$ and/or albuminuria on two occasions spaced by 2 weeks. Stages of CKD were classified according to the National Kidney Foundation Kidney Disease Outcomes Quality Initiative (NKF KDOQI) guideline as [21]: stage 1 , eGFR $\geq 90 \mathrm{ml} / \mathrm{min} / 1.73 \mathrm{~m}^{2}$ with albuminuria; stage 2, eGFR of $60-89.9 \mathrm{ml} / \mathrm{min} / 1.73 \mathrm{~m}^{2}$ with albuminuria, and stages 3,4 and 5 as eGFR of $30-$ $59.9, \quad 15-29.9$ and $<15 \mathrm{ml} / \mathrm{min} / 1.73 \mathrm{~m}^{2}$, respectively. Stage 3 was further classified into 3A $(45-59.9 \mathrm{ml} / \mathrm{min} /$ $\left.1.73 \mathrm{~m}^{2}\right)$ and $3 B\left(30-44.9 \mathrm{ml} / \mathrm{min} / 1.73 \mathrm{~m}^{2}\right)$ [22].

\section{Statistical analysis}

Data were entered into "EpiData 3.1" software and analyzed using SPSS version 20.0 (SPSS, Chicago, IL, USA). Data were expressed as means \pm standard deviation (SD) or percentage. Comparisons between groups were done by chi square $\left(\mathrm{x}^{2}\right)$ test or $t$-test as appropriate. Multivariable stepwise logistic regression was used to calculate adjusted odds ratios (OR) and the corresponding 95\% confidence intervals $(\mathrm{CI}) . P$ value $<0.05$ was used to indicate statistical significance.

\section{Results}

Demographic and clinical characteristics of participants A total of 323 patients were included in the study. The mean $( \pm$ SD) age of the participants was $44 \pm 15.7$ years (ranging from 18 to 77 years), and 168 (52.0\%) were males. Of the participants, 173 (53.6\%) were type 2 diabetics, 186 (57.6\%) had duration of diabetes less than 5 years, and 62 (19.2\%) had a family history of kidney disease. Mean BMI was $22.37 \pm 3.94 \mathrm{Kg} / \mathrm{m}^{2}$. The mean systolic and diastolic $\mathrm{BP}$ of the participants was $125.6 \pm 18$ and $78.4 \pm 8 \mathrm{mmHg}$, respectively. Mean FBG was $190.15 \pm 87.89 \mathrm{mg} / \mathrm{dl}$. Mean $\mathrm{SCr}$ was $1.01 \pm 0.33 \mathrm{mg} / \mathrm{dl}$. The mean eGFR was $100.6 \pm$ $35.04 \mathrm{ml} / \mathrm{min} / 1.73 \mathrm{~m}^{2}$ (Table 1).

\section{Prevalence of CKD}

The overall prevalence of CKD stage 1-5 was $26.3 \%$ (95\% CI, 20.8 to 31.8) (Table 2). Of the total participants, $13.0 \%$ had an eGFR of $<60 \mathrm{ml} / \mathrm{min} / 1.73 \mathrm{~m}^{2}$ (stage
Table 1 Demographic and clinical characteristics of study participants $(n=323)$

\begin{tabular}{|c|c|c|}
\hline Characteristics & Category & N (\%) \\
\hline \multicolumn{2}{|l|}{ Age (year), means $\pm S D$} & $44 \pm 15.7$ \\
\hline \multirow[t]{5}{*}{ Age group, n (\%) } & 18-39 Years & $119(36.8)$ \\
\hline & 40-49 Years & $75(23.2)$ \\
\hline & $50-59$ Years & $62(19.2)$ \\
\hline & 60-69 Years & $48(14.9)$ \\
\hline & $\geq 70$ Years & $19(5.9)$ \\
\hline \multirow[t]{2}{*}{ Sex, n (\%) } & Male & $155(48.0)$ \\
\hline & Female & $168(52.0)$ \\
\hline \multirow[t]{2}{*}{ Type of diabetes, n (\%) } & Type 1 & $150(46.4)$ \\
\hline & Type 2 & $173(53.6)$ \\
\hline \multirow[t]{3}{*}{ Duration of diabetes, n (\%) } & $<5$ Years & $186(57.6)$ \\
\hline & $5-9.9$ Years & $97(30.0)$ \\
\hline & $\geq 10$ Years & $40(12.4)$ \\
\hline \multicolumn{2}{|c|}{ Family history of kidney disease, $\mathrm{n}(\%)$} & $62(19.2)$ \\
\hline \multicolumn{2}{|c|}{ Body mass index $\left(\mathrm{Kg} / \mathrm{m}^{2}\right)$, means $\pm \mathrm{SD}$} & $22.37 \pm 3.94$ \\
\hline \multicolumn{2}{|l|}{ Obesity, n (\%) } & $21(6.5 \%)$ \\
\hline \multicolumn{2}{|l|}{ Hypertension, n (\%) } & $99(30.7 \%)$ \\
\hline \multicolumn{2}{|c|}{ Systolic BP (mmHg), means \pm SD } & $125.6 \pm 18$ \\
\hline \multicolumn{2}{|c|}{ Diastolic BP (mmHg), means \pm SD } & $78.4 \pm 81$ \\
\hline \multicolumn{2}{|c|}{ Fasting Serum Glucose $(\mathrm{mg} / \mathrm{dl})$, means $\pm \mathrm{SD}$} & $190.15 \pm 87.89$ \\
\hline \multicolumn{2}{|c|}{ Serum Creatinine $(\mathrm{mg} / \mathrm{dl})$, means $\pm \mathrm{SD}$} & $1.01 \pm 0.33$ \\
\hline \multicolumn{2}{|c|}{$\mathrm{eGFR}_{\text {MDRD }}\left(\mathrm{ml} / \mathrm{min} / 1.73 \mathrm{~m}^{2}\right)$, means $\left.\pm \mathrm{SD}\right)$} & $100.6 \pm 35.04$ \\
\hline
\end{tabular}

3-5 CKD). Only $23.5 \%$ of the participants with advanced stage CKD had $\mathrm{SCr}$ values $>1.5 \mathrm{mg} / \mathrm{dl}$ (the traditional criteria for diagnosing CKD; eGFR $<60 \mathrm{ml} / \mathrm{min} / 1.73 \mathrm{~m}^{2}$ ) [23]. Albuminuria was present in $18 \%$ of total participants, but was absent in $31.8 \%$ of those with eGFR $<60$ $\mathrm{ml} / \mathrm{min} / 1.73 \mathrm{~m}^{2}$ (stage 3-5 CKD). The prevalence of CKD was $46.9 \%$ in participants $>60$ years old and $22.6 \%$ in those $\leq 60$ years old $(P<0.001)$. CKD prevalence was lower in males $(14.8 \%)$ than in females $(36.9 \%$; $P<$ $0.001)$.

Table 2 Prevalence of CKD stages according to K/DOQI classification $(N=323)$

\begin{tabular}{lll}
\hline CKD Stage & eGFR $\left(\mathrm{ml} / \mathrm{min} / 1.73 \mathrm{~m}^{2}\right)$ & Number $(\%)$ \\
\hline 1 & $\geq 90$ & $29(9.0)$ \\
2 & $60-89.9$ & $14(4.3)$ \\
3 & $30-59.9$ & $38(11.8)$ \\
3A & $45-59.9$ & $33(10.2)$ \\
$3 B$ & $30-44.9$ & $5(1.6)$ \\
4 & $15-29.9$ & $4(1.2)$ \\
All stages of CKD & & $85(26.3)$ \\
Albuminuria & & $58(18.0)$ \\
\hline
\end{tabular}


Table 3 Multivariate logistic regression analysis of risk factors for CKD in our cohort of diabetic patients

\begin{tabular}{llll}
\hline Variable & Odds ratio & $95 \%$ Confidence interval & $P$-value \\
\hline Age $>60$ years & 2.48 & $1.13-5.43$ & 0.023 \\
Female gender & 4.93 & $2.56-9.50$ & 0.001 \\
Diabetes duration $\geq 10$ years & 5.16 & $2.13-12.51$ & $<0.001$ \\
Family history of kidney disease & 2.37 & $1.17-4.79$ & 0.016 \\
Hypertension & 3.37 & $1.45-7.86$ & 0.005 \\
Mean fasting blood glucose $>130 \mathrm{mg} / \mathrm{dl}$ & 2.58 & $1.19-5.61$ & 0.016 \\
\hline
\end{tabular}

In univariate analysis, the factors associated with CKD were older age $(P<0.001)$, female gender $(P<0.001)$, decreased literacy $(P=0.017)$, low monthly income $(P=$ $0.042)$, long duration of diabetes $(P<0.001)$, family history of kidney disease $(P<0.001)$, hypertension $(P<$ $0.001)$, high systolic BP $(P=0.005)$, and poor glycemic control $(P<0.001)$. In the multivariable analysis, older age $(\mathrm{OR}=2.48, \mathrm{CI} 1.13-5.43)$, gender $(\mathrm{OR}=4.93, \mathrm{CI}$ 2.56-9.50), longer duration of diabetes $(\mathrm{OR}=5.16$, CI 2.13-12.51), hypertension ( $\mathrm{OR}=3.37$, CI 1.45-7.86), a family history of kidney disease $(\mathrm{OR}=2.37$, CI $1.17-$ 4.79 ), and poor glycemic control (OR 2.58, CI 1.19-5.61) were significantly associated with CKD (Table 3).

\section{CKD awareness}

Overall, $10.6 \%$ of 85 individuals with CKD reported being told by a doctor or other health care professional that they had kidney disease. The proportion of individuals who were aware of their disease increased with worsening of CKD stages: $3.4 \%$ of with stage 1, $21.4 \%$ with stage $2,5.3 \%$ with stage 3 , and $75.0 \%$ with stage 4 . Awareness for all individuals with advanced stages of CKD (stage 3-5 CKD) was only $11.9 \%$. For logistic regression, CKD awareness was used as the outcome variable. The covariates were age, sex, duration of diabetes, family history of kidney disease, obesity, serum creatinine and albuminuria. In multivariable analysis, having albuminuria $(\mathrm{OR}=4.08,1.54-10.85)$, abnormal serum creatinine $(\mathrm{OR}=5.16,1.52-17.48)$, and a family history of kidney disease $(\mathrm{OR}=2.89,1.07-7.80)$ and being obese $(\mathrm{OR}=5.53,2.18-14.04)$ were all statistically significantly associated with greater awareness (Table 4).

\section{Discussion}

The prevalence of CKD of any stage [1-5] in our diabetic outpatients was $26.3 \%$, with stage 3 being dominant
(11.8\%). The overall prevalence of CKD observed in our study was higher than $21.8 \%$ prevalence reported from the University of Gondar Hospital study in Northwest Ethiopia [24] and closer to that of $27.5 \%$ reported in the Netherland study [25], 27.9\% in the Spain PERCEDIME2 study [26] and $29.6 \%$ in the Chinese study [27]. However, our prevalence estimate of CKD using a similar definition of eGFR prediction equation was lower than that of $39 \%$ reported in Kinshasa, the democratic republic of Congo study [28], 34.1\% in Catalonia (Spain) study [29], and $42.3 \%$ in the Japanese study [30]. These differences in prevalence might be because of the differences in creatinine assays and calibration, albumin assays or differences in case-mix (in terms of diabetes type).

A high prevalence of advanced stages CKD (defined as eGFR $<60 \mathrm{ml} / \mathrm{min} / 1.73 \mathrm{~m}^{2}$; stages $3-5$ CKD), $13.0 \%$ was found in our studied diabetic outpatients using eGFR equations. This is in accordance with other studies that found a prevalence of $3.9-31 \%$ of eGFR $\mathrm{MDRD}<60 \mathrm{ml} /$ $\mathrm{min} / 1.73 \mathrm{~m}^{2}$ [11, 24, 31]. Interestingly, only $23.5 \%$ of those with advanced stages CKD had serum creatinine level $>1.5 \mathrm{mg} / \mathrm{dl}$, the point frequently used by clinicians for diagnosing CKD (eGFR $<60 \mathrm{ml} / \mathrm{min} / 1.73 \mathrm{~m}^{2}$; stages 3-5 CKD). This is in accordance with our previous study, reporting only $48.7 \%$ of diabetic outpatients with eGFR MDRD $<60 \mathrm{ml} / \mathrm{min} / 1.73 \mathrm{~m}^{2}$ had abnormal serum creatinine values [32]. We also found that albuminuria was absent in $31.8 \%$ of subjects with CKD stages 3 to 5 $\left(\mathrm{eGFR}<60 \mathrm{ml} / \mathrm{min} / 1.73 \mathrm{~m}^{2}\right)$. In line with this a recent study found that approximately one half (46.6\%) of diabetics with CKD had reduced eGFR without albuminuria [33]. Inadequacies of CKD diagnosis in diabetes from routine clinical assessment also are mentioned frequently in the literature $[11,12,31]$, indicating the need for a simple functional measurement of GFR, as provided using the eGFR.

Table 4 Factors associated with CKD awareness

\begin{tabular}{llll}
\hline Variable & Odds ratio & $95 \%$ Confidence interval & $P$ value \\
\hline Albuminuria & 4.08 & $1.54-10.85$ & 0.017 \\
Serum creatinine $>1.5 \mathrm{mg} / \mathrm{dl}$ & 5.16 & $1.52-17.48$ & 0.001 \\
Family history of kidney disease & 2.89 & $1.07-7.80$ & 0.002 \\
Obesity $\left(\mathrm{BMl} \geq 30 \mathrm{~kg} / \mathrm{m}^{2}\right)$ & 5.53 & $2.18-14.04$ & 0.042 \\
\hline
\end{tabular}


Our data shows that CKD awareness rates in diabetic outpatients are low: $3.4 \%$ for people with stage 1 CKD, $21.4 \%$ for stage $2,5.3 \%$ for stage 3 , and $75.0 \%$ for stage 4. These findings complement with the ADD-CKD Study [13], in which $1.1 \%$ of diabetics with Stage 1, 4.9\% with Stage 2, $18.0 \%$ with Stage 3, 52.9\% with Stage 4 were aware of their CKD. Awareness among KEEP participants with diabetes and CKD was low at $9.4 \%$, being $6 \%$ in patients with CKD stages 1 and 2, and 10.9\% in those with advanced stages of CKD [34]. Our finding of higher CKD awareness in patients with a family history of renal disease is supported by the KEEP data, which suggested that a family history of kidney disease should make CKD awareness more likely [35]. The low CKD awareness, which is magnified by the use of inadequate screening tests such as serum creatinine and dipstick albuminuria in this study, indicates that primary care physicians may not be able to identify diabetics with CKD based on the laboratory report in hand [13]. Such a finding therefore indicates the need of routine use of eGFR to improve the recognition and thus, awareness of CKD in primary care.

Currently, most laboratories in Ethiopia do not report an eGFR when renal profile or serum creatinine is ordered. As blood test for serum creatinine or urine dipstick for albuminuria are used by clinicians to determine the presence or absence of kidney disease, this form of screening can lead to underrecognition of CKD $[11,31]$ and thus low disease awareness [36]. Early detection and awareness of CKD in diabetics can therefore be improved by routine eGFR reporting and primary care education on the impact of introducing eGFR into the routine screening of CKD to facilitate its early recognition and the institution of effective preventive measures for modifying disease outcomes and improving diabetes care, as shown by related studies [37-39]. Supporting this, a recent study noted that determination of the eGFR of even newly diagnosed asymptomatic diabetics with a view to creating awareness for early screening, evaluation and intervention would be desirable [40]. GFR can be estimated by the Cockcroft and Gault [41] or the MDRD study equations, as indicated by the NKF and the American Diabetes Association [42].

The 4-variable MDRD study equation was used for estimating GFR in this study, as recommended by the NKF KDOQI guidelines, as it generates a GFR estimation normalized to a standard body surface area (1.73 $\mathrm{m}^{2}$ ) using sex, age, race and serum creatinine only. Because it is more accurate than the Cockcroft-Gault equation in CKD patients with diabetes [43], and is not biased by body weight [44] and more robust when glucose control is poor [45]; the MDRD equation appears to be preferable. Additionally, the routine laboratory estimation of GFR using the simplified MDRD equation has been also shown to facilitate the recognition and documentation of early CKD and increase awareness of CKD in such patients with diabetes [37, 38]. There is also evidence that the estimation of early GFR loss is more accurate with the MDRD equation than with the recently developed Chronic Kidney Disease Epidemiology (CKD-EPI) equation in diabetic population [46]. Further studies are needed to investigate whether eGFR reporting with the MDRD equation facilitates the recognition and awareness of CKD in Ethiopian diabetic adults.

This study was the first of its type to determine the prevalence and awareness of CKD among African diabetic adult outpatients but has some limitations. The study's limitations include the small sample size of our study population and the fact that data was taken from a single hospital, thus our sample cannot be considered representative of all diabetic patients in the country. On the other hand, more than half $(57.6 \%)$ of the patients had a short duration of diabetes, and this may explain some of the differences with other studies. We used the MDRD study equation, the validation of which is lacking among Ethiopian diabetic adults. The CKD-EPI equation may be superior in estimating the GFR but the best eGFR equation for Ethiopian adults has not yet been determined. Finally, the measurement of serum creatinine was not standardized; this might influence the performance of eGFR equations.

\section{Conclusion}

In conclusion, this study demonstrated a high prevalence and low awareness of CKD among diabetic adults attending the outpatient diabetes clinic of Northeast Ethiopia. Current screening methods, serum creatinine or urine dipstick for albuminuria, underestimates the presence of clinically significant CKD in our diabetic outpatient. More diagnostic strategies for CKD screening among diabetic adults and primary care education on the impact of detecting CKD in the early stage are needed to prevent adverse outcomes and improve diabetes care.

\section{Supplementary information}

Supplementary information accompanies this paper at https://doi.org/10. 1186/s12882-020-01768-y.

Additional file 1:. Questionnaire. English version of the questionnaire used during the study.

\section{Abbreviations}

BMI: Body mass index; BP: Blood pressure; CKD: Chronic kidney disease; $\mathrm{DRH}$ : Dessie Referral hospital; eGFR: Estimated glomerular filtration rate

\section{Acknowledgements}

The authors would like to acknowledge data collectors, and staff of diabetic clinic of Dessie Referral hospital for collecting the data. 


\section{Authors' contributions}

TF and ZT were involved in the conception, design, analysis, interpretation, report writing and manuscript writing. All authors read and approved the final manuscript version submitted for publication.

\section{Funding}

The study was funded by Wollo University. The funders had no role in study design, data collection and analysis, decision to publish, or preparation of the manuscript.

\section{Availability of data and materials}

The data of this study can't be shared publicly due to presence of sensitive (confidential) participants' information and additional data than that used in this publication. But the data are available from the corresponding author on reasonable request.

\section{Ethics approval and consent to participate}

Study protocol was approved by the Institutional Review Board of College of Medicine and Health Sciences, Wollo University. All participants provided verbal as well as written informed consent prior to study entry. Confidentiality was assured for all the information provided and personal identifiers were not included on questionnaire. Those participants who were found to have CKD were linked to the attending clinicians in the diabetic clinic for follow-ups.

\section{Consent for publication}

Not applicable.

\section{Competing interests}

The authors declare that they have no competing interests.

\section{Author details}

'Department of Clinical Laboratory Science, College of Medicine and Health Sciences, Wollo University, Dessie, Ethiopia. ${ }^{2}$ Department of Medical Laboratory Sciences, College of Health Sciences, Addis Ababa University, Addis Ababa, Ethiopia.

\section{Received: 25 March 2019 Accepted: 19 March 2020}

\section{Published online: 15 April 2020}

\section{References}

1. Levey A, Atkins R, Coresh J, Cohen E, Collins A, Eckardt K-U, et al. Chronic kidney disease as a global public health problem: approaches and initiatives - a position statement from kidney disease improving global outcomes. Kidney Int. 2007;72:247-59.

2. Jha V, Garcia-Garcia G, Iseki K, Li Z, Naicker S, Plattner B, et al. Chronic kidney disease: global dimension and perspectives. Lancet. 2013;382(9888): 260-72.

3. Stanifer JW, Muiru A, Jafar TH, Patel UD. Chronic kidney disease in low- and middle-income countries. Nephrol Dial Transplant. 2016;31(6):868-74.

4. McFarlane SI, McCullough PA, Sowers JR, Soe K, Chen S-C, Li S, et al. Comparison of the CKD Epidemiology Collaboration (CKD-EPI) and Modification of Diet in Renal Disease (MDRD) study equations: prevalence of and risk factors for diabetes mellitus in CKD in the Kidney Early Evaluation Program (KEEP). Am J Kidney Dis. 2011:57(3):S24-31.

5. Ninomiya T, Perkovic V, de Galan BE, Zoungas S, Pillai A, Jardine M, et al. Albuminuria and kidney function independently predict cardiovascular and renal outcomes in diabetes. J Am Soc Nephrol. 2009;20(8):1813-21.

6. Fox CS, Matsushita K, Woodward M, Bilo HJG, Chalmers J, Heerspink HJ, et al. Associations of kidney disease measures with mortality and end-stage renal disease in individuals with and without diabetes: a meta-analysis. Lancet. 2012;380(9854):1662-73.

7. Laliberté F, Bookhart BK, Vekeman F, Corral M, Duh MS, Bailey RA, et al. Direct all-cause health care costs associated with chronic kidney disease in patients with diabetes and hypertension: a managed care perspective. J Manag Care Pharm. 2009:15(4):312-22

8. Satyavani K, Kothandan H, Jayaraman M, Viswanathan V. Direct costs associated with chronic kidney disease among type 2 diabetic patients in India. Indian J Nephrol. 2014;24(3):141-7.
9. Thomas MC, Cooper ME, Zimmet P. Changing epidemiology of type 2 diabetes mellitus and associated chronic kidney disease. Nat Rev Nephrol. 2016;12(2):73-81.

10. Kainz A, Hronsky M, Stel VS, Jager KJ, Geroldinger A, Dunkler D, et al. Prediction of prevalence of chronic kidney disease in diabetic patients in countries of the European Union up to 2025. Nephrol Dial Transpl. 2015; 30(Suppl 4):iv113-8.

11. Middleton RJ, Foley RN, Hegarty J, Cheung CM, McElduff P, Gibson JM, et al. The unrecognized prevalence of chronic kidney disease in diabetes. Nephrol Dial Transplant. 2006;21:88-92.

12. Bachorzewska-Gajewska H, Malyszko J, Malyszko JS, Musial W, Dobrzycki S. Undiagnosed renal impairment in patients with and without diabetes with normal serum creatinine undergoing percutaneous coronary intervention. Nephrology (Carlton). 2006;11(6):549-54

13. Szczech LA, Stewart RC, Su H-L, DeLoskey RJ, Astor BC, Fox CH, et al. Primary care detection of chronic kidney disease in adults with type-2 diabetes: the ADD-CKD study (awareness, detection and drug therapy in type 2 diabetes and chronic kidney disease). PLoS One. 2014;9(11):e110535.

14. $\mathrm{KDOQI}$ KDOQI clinical practice guidelines and clinical practice recommendations for diabetes and chronic kidney disease. Am J Kidney Dis. 2007:49(2 Suppl 2):S12-154.

15. Howard K, White S, Salkeld G, McDonald S, Craig JC, Chadban S, et al. Costeffectiveness of screening and optimal management for diabetes, hypertension, and chronic kidney disease: a modeled analysis. Value Health. 2010;13(2):196-208.

16. Lee SJ, Chung CW. Health behaviors and risk factors associated with chronic kidney disease in Korean patients with diabetes: the fourth Korean National Health and nutritional examination survey. Asian Nurs Res. 2014;8(1):8-14.

17. Onyenwenyi C, Ricardo AC. Impact of lifestyle modification on diabetic kidney disease. Curr Diab Rep. 2015;15(9):60

18. Dunkler D, Kohl M, Heinze G, Teo KK, Rosengren A, Pogue J, et al. Modifiable lifestyle and social factors affect chronic kidney disease in highrisk individuals with type 2 diabetes mellitus. Kidney Int. 2015;87(4):784-91.

19. Noubiap JJN, Naidoo J, Kengne AP. Diabetic nephropathy in Africa: a systematic review. World J Diabetes. 2015;6(5):759-73.

20. Levey AS, Greene T, Kusek JW, Beck GJ. A simplified equation to predict glomerular filtration rate from serum creatinine. J Am Soc Nephrol. 2000;11: $155 \mathrm{~A}$

21. National Kidney Foundation. K/DOQI clinical practice guidelines for chronic kidney disease: evaluation, classification, and stratification. Ann Intern Med. 2002;39(2):S1-266

22. Hogan M. KDIGO conference proposes changes to CKD classification, but not to the definition. Nephrol. 2009;2(12):9-10

23. Myers GL, Miller WG, Coresh J, Fleming J, Greenberg N, Greene T, et al. Recommendations for improving serum Creatinine measurement: a report from the laboratory working Group of the National Kidney Disease Education Program. Clin Chem. 2006;52(1):5-18.

24. Damtie S, Biadgo B, Baynes HW, Ambachew S, Melak T, Asmelash D, et al. Chronic kidney disease and associated risk factors assessment among diabetes mellitus patients at a tertiary hospital, Northwest Ethiopia. Ethiop J Sci. 2018;28(6):691-700.

25. Van der Meer V, Wielders HPM, Grootendorst DC, de Kanter JS, Sijpkens YW, Assendelft WJ, et al. Chronic kidney disease in patients with diabetes mellitus type 2 or hypertension in general practice. Br J Gen Pract. 2010;60: 884-90.

26. Rodriguez-Poncelas A, Garre-Olmo J, Franch-Nadal J, Diez-Espino J, MundetTuduri $X$, la Puente JB-D, et al. Prevalence of chronic kidney disease in patients with type 2 diabetes in Spain: PERCEDIME2 study. BMC Nephrol. 2013;14:46.

27. Jia W, Gao X, Pang C, Hou X, Bao Y, Liu W, et al. Prevalence and risk factors of albuminuria and chronic kidney disease in Chinese population with type 2 diabetes and impaired glucose regulation: Shanghai diabetic complications study (SHDCS). Nephrol Dial Transpl. 2009;24:3724-31.

28. Sumaili EK, Cohen EP, Zinga CV, Krzesinski J-M, Pakasa NM, Nseka NM. High prevalence of undiagnosed chronic kidney disease among at-risk population in Kinshasa, the Democratic Republic of Congo. BMC Nephrol. 2009;10:18.

29. Coll-de-Tuero G, Mata-Cases M, Rodriguez-Poncelas A, Pepió JM, Roura P Benito B, et al. Chronic kidney disease in the type 2 diabetic patients: prevalence and associated variables in a random sample of 2642 patients of a Mediterranean area. BMC Nephrol. 2012;13:87. 
30. Ohta M, Babazono T, Uchigata Y, Iwamoto Y. Comparison of the prevalence of chronic kidney disease in Japanese patients with type 1 and type 2 diabetes. Diabet Med. 2010;27(9):1017-23.

31. New JP, Middleton RJ, Klebe B, Farmer CKT, de Lusignan S, Stevens PE, et al. Assessing the prevalence, monitoring and management of chronic kidney disease in patients with diabetes compared with those without diabetes in general practice. Diabet Med. 2007;24(4):364-9.

32. Fiseha T, Kassim M, Yemane T. Chronic kidney disease and underdiagnosis of renal insufficiency among diabetic patients attending a hospital in southern Ethiopia. BMC Nephrol. 2014;15:198.

33. Laranjinha I, Matias P, Mateus S, Aguiar F, Pereira P, Santos MP, et al, Diabetic kidney disease: is there a non-albuminuricphenotype in type 2 diabetic patients? Nefrologia. 2016;36(5):503-9.

34. Whaley-Connell A, Sowers JR, McCullough PA, Roberts T, McFarlane SI, Chen $\mathrm{S}-\mathrm{C}$, et al. Diabetes mellitus and CKD awareness: the kidney early evaluation program (KEEP) and National Health and nutrition examination survey (NHANES). Am J Kidney Dis. 2009;53(S4):S11-21.

35. Whaley-Connell A, Bomback AS, McFarlane SI, Li S, Roberts T, Chen S-C, et al. Diabetic cardiovascular disease predicts chronic kidney disease awareness in the kidney early evaluation program. Cardiorenal Med. 2011; 1(1):45-52.

36. Minutolo R, Nicola LD, Mazzaglia G, Postorino M, Cricelli C, Mantovani LG, et al. Detection and awareness of moderate to advanced CKD by primary care practitioners: a cross-sectional study from Italy. Am J Kidney Dis. 2008; 52:444-53.

37. Wyatt C, Konduri V, Eng J, Rohatgi R. Reporting of estimated GFR in the primary care clinic. Am J Kidney Dis. 2007:49:634-41.

38. Noble E, Johnson DW, Gray N, Hollett P, Hawley CM, Campbell SB, et al. The impact of automated eGFR reporting and education on nephrology service referrals. Nephrol Dial Transpl. 2008;23:3845-50.

39. Cueto-Manzano AM, Martinez-Ramirez HR, Corte's-Sanabria L. Comparison of primary health-care models in the management of chronic kidney disease. Kidney Int Suppl. 2013;3:210-4.

40. Ajayi S, Mamven M, Ojji D. eGFR and chronic kidney disease stages among newly diagnosed asymptomatic Hypertensives and diabetics seen in a tertiary health Center in Nigeria. Ethn Dis. 2014;24(2):220-5.

41. Cockcroft DW, Gault MH. Prediction of creatinine clearance from serum creatinine. Nephron. 1976;16:31-41.

42. American Diabetes Association. Standards of medical care in diabetes 2011. Diabetes Care. 2011;34(Supp 1):S11-61.

43. Rigalleau V, Lasseur C, Perlemoine C, Barthe N, Raffaitin C, Liu C, et al. Estimation of glomerular filtration rate in diabetic subjects: Cockcroft formula or modification of diet in renal disease study equation? Diabetes Care. 2005:28:838-43.

44. Rigalleau V, Lasseur C, Perlemoine C, Barthe N, Raffaitin C, Chauveau P, et al. Cockcroft-Gault formula is biased by body weight in diabetic patients with renal impairment. Metabolism. 2006;55:108-12.

45. Rigalleau V, Lasseur C, Raffaitin C, Perlemoine C, Barthe N, Chauveau P, et al. Glucose control influences glomerular filtration rate and its prediction in diabetic subjects. Diabetes Care. 2009:29:1491-5

46. Schwandt A, Denkinger M, Fasching P, Pfeifer M, Wagner C, Weiland J, et al. Comparison of MDRD, CKD-EPI, and Cockcroft-Gault equation in relation to measured glomerular filtration rate among a large cohort with diabetes. J Diabetes Complicat. 2017;31(9):1376-83.

\section{Publisher's Note}

Springer Nature remains neutral with regard to jurisdictional claims in published maps and institutional affiliations.

Ready to submit your research? Choose BMC and benefit from:

- fast, convenient online submission

- thorough peer review by experienced researchers in your field

- rapid publication on acceptance

- support for research data, including large and complex data types

- gold Open Access which fosters wider collaboration and increased citations

- maximum visibility for your research: over $100 \mathrm{M}$ website views per year

At BMC, research is always in progress.

Learn more biomedcentral.com/submissions 